\title{
Idiopathic Yellow Nail Syndrome Successfully Treated with OK-432
}

\author{
Toru Yamagishi, Nobuyuki Hatanaka, Hirotaka Kamemura, Ichiro Nakazawa, Yusuke Hirano, \\ Norio Kodaka, Atsuo Miura, Asako Kitahara, Tetsuro Sawata, Kimio Hosaka and Ken Sanno
}

\begin{abstract}
A 70-year-old female presented with yellow discoloration of the nail beds of all fingers and toes, as well as bilateral pleural effusions. The patient was diagnosed as having the yellow nail syndrome based on the triad of yellow nails, lymphedema, and pleural effusions. The patient's intractable bilateral pleural effusion was treated with pleurodesis using OK-432. The treatment prevented the accumulation of pleural fluid for a long period of time. Pleural effusion associated with yellow nail syndrome is thought to be difficult to treat; however, this patient's excellent clinical course suggests that pleurodesis with OK-432 could be used to treat the disease in the future.
\end{abstract}

Key words: chemical pleurodesis, lymphedema, OK-432, pleural effusion, yellow nail

(DOI: 10.2169/internalmedicine.46.0022)

\section{Introduction}

Yellow nail syndrome is a disorder characterized by the triad of yellow nails, lymphedema, and pulmonary disease, such as pleural effusion and bronchodilatation. Idiopathic development of the disease is relatively rare. We treated a patient with yellow nail syndrome with intractable bilateral pleural effusion. In this patient, pleurodesis with OK-432 prevented accumulation of pleural fluid for a long period of time. We report this case and review the literature.

\section{Case Report}

A 70-year-old female reported that, since about 1980, she was aware of thickening, reduction in the growth rate (1 $\mathrm{mm} / 3$ months), and yellow discoloration of the nail beds of all fingers and toes; however, she did not seek medical attention. In June 1999, a chest X-ray taken during a health examination revealed bilateral small pleural effusions, but no treatment was given. The patient began experiencing exertional dyspnea in November 2000 and sought medical attention in December 2000. Marked bilateral pleural effusion was noted, and the patient was hospitalized. The patient was treated with an antituberculous agent and a diuretic, but her symptoms did not improve. Since the cause of her symptoms could not be identified, the patient was transferred to our hospital in mid-February 2001.

The patient was $150 \mathrm{~cm}$ tall and weighed $48 \mathrm{~kg}$. Her body temperature was $36.8^{\circ} \mathrm{C}$. The patient's blood pressure was $114 / 80 \mathrm{mmHg}$; the pulse was regular at 80 beats/min, and the respiratory rate was $18 / \mathrm{min}$. Her palpebral conjunctiva did not appear anemic, and the bulbar conjunctiva was not icteric. Heart sounds were normal. Vesicular breath sounds were weaker bilaterally in the lower lung fields. The abdomen was flat and soft, and there was mild pitting edema on both upper and lower extremities. The nail beds of all fingers and toes were thicker and had become a muddy yellow; their growth rate had decreased markedly (1 $\mathrm{mm} / 3$ months) (Fig. 1). The neurological examination was normal.

The complete blood count was normal. On biochemical testing, she was found to have a decreased total protein and albumin; her renal function was normal, and her inflammatory response was weak. Serum rheumatoid factor, antinuclear antibody, and tumor markers were also negative (Table 1). The pleural fluid was a clear pale yellow and appeared exudative; the adenosine deaminase level was low. Pleural fluid cultures, including acid-fast bacteria, were negative. Tumor markers, such as carcinoembryonic antigen, 
were not elevated; cytology was negative for malignancy. The pleural fluid cell count was 1924/3 and continued to increase as the patient was being followed; $98 \%$ of the cells were lymphocytes (Table 2). Pleural biopsy revealed only fibrous thickening.

The chest X-ray revealed blunting of bilateral costophrenic angles, and meniscus signs were observed, suggesting pleural fluid accumulation (Fig. 2). The chest CT also showed bilateral pleural fluid accumulation, but no obvious inflammatory changes or a tumor lesion were seen. There was no mediastinal lymph node swelling (Fig. 2). Cardiac

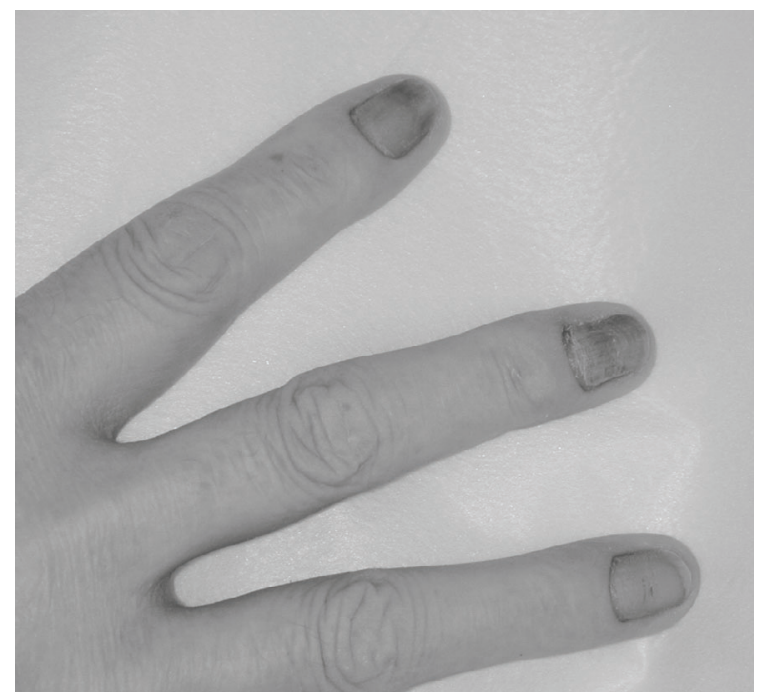

Figure 1. A photograph of the left hand. The nail beds of the fingers are thicker and appear muddy yellow; the growth rate was markedly decreased (1 mm / 3 months). function was normal on echocardiography.

The site of edema on the extensor side of the left lower thigh was biopsied. The epidermis was flat and extended, and a mild perivascular lymphocytic infiltration was observed in the dermis. Mild dilation of lymph vessels was observed, suggesting lymphedema.

Since the patient had yellow nails, the nail clippings were cultured, but no fungus was isolated. The patient was diagnosed as having yellow nail syndrome due to the presence of the 3 major characteristics of this syndrome. There were no signs of malignancy, and the patient did not have a history of treatment with an antirheumatic drug, such as dpenicillamine or bucillamine. Therefore, this patient appeared to have idiopathic yellow nail syndrome. After admission, the bilateral pleural effusions continued to increase markedly, and the patient developed respiratory failure requiring ventilator support. Since ventilator withdrawal was difficult, a tracheostomy was performed, and the patient required continuous airway positive pressure breathing. Trocars were placed in the pleural cavity, but continuing drainage of the pleural fluids resulted in worsening hypoproteinemia and hypoalbuminemia due to the continuous leakage of pleural fluid protein and pleural fluid albumin. Therefore, after informed consent was obtained, pleurodesis with OK432 10KE was done 3 times each on both sides. As a result, the amount of pleural fluid drainage decreased, and the trocars could be removed. Due to hypoventilation, thought to be caused by the bilateral pleurodesis, ventilator support could not be completely withdrawn. However, the patient was discharged on a home ventilator. During the last three years, the bilateral pleural fluid has not increased.

Table 1. Laboratory Findings on Admission

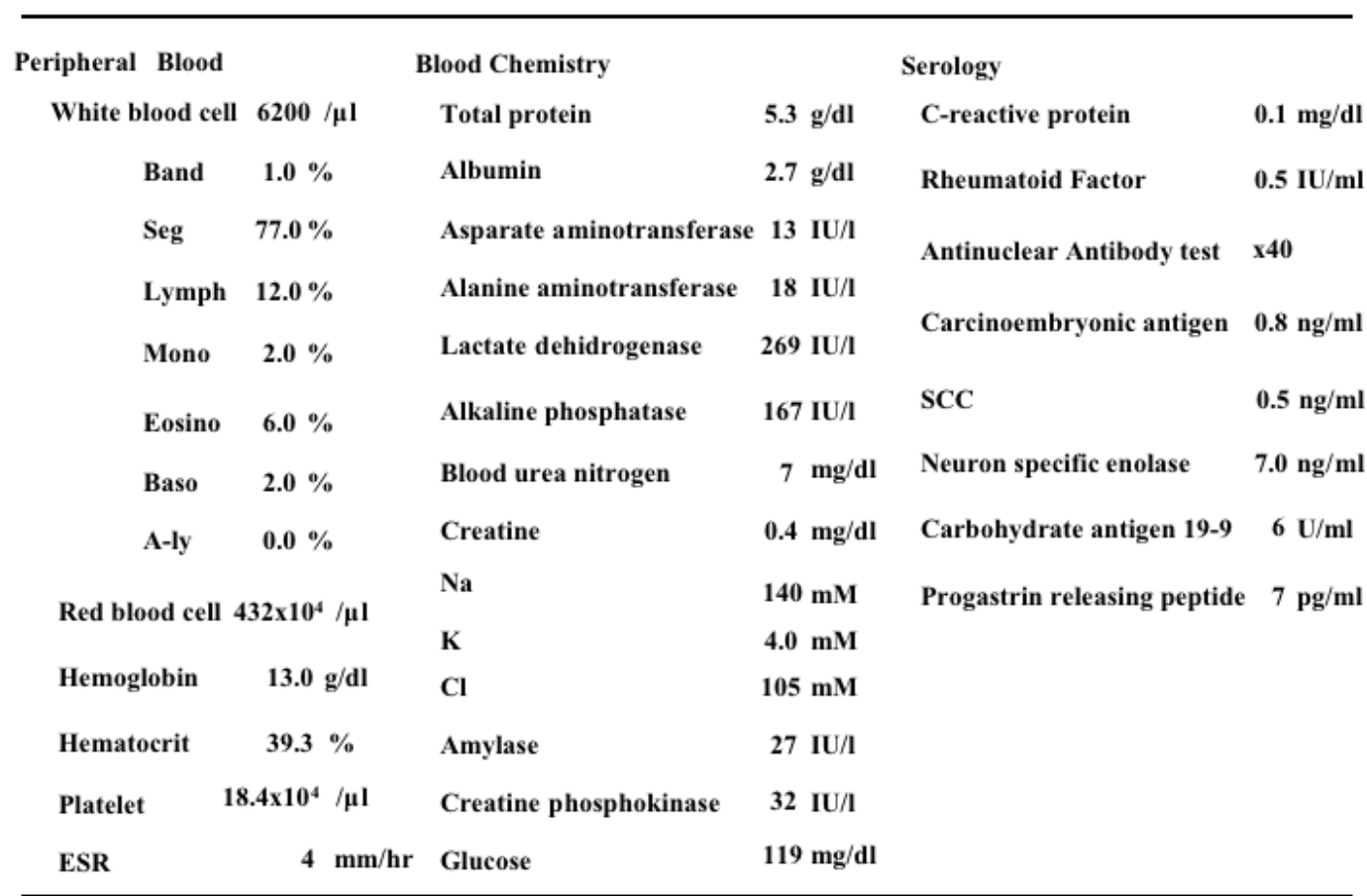

SCC : Squamous cell carcinoma related antigen 
Table 2. Laboratory Findings of Pleural Effusion

\begin{tabular}{|c|c|c|c|}
\hline Color & yellow & Rheumatoid Factor & $0.5 \Pi \mathrm{IU} / \mathrm{ml}$ \\
\hline Gravity & 1.028 & Carcin oembry onic antigen & $0.7 \mathrm{ng} / \mathrm{ml}$ \\
\hline Total protein & $4.0 \mathrm{~g} / \mathrm{dl}$ & Squamous cell carcinoma related antigen & $0.7 \mathrm{ng} / \mathrm{ml}$ \\
\hline Albumin & $2.2 \mathrm{~g} / \mathrm{dl}$ & Neuron specific enolase & $9.2 \mathrm{ng} / \mathrm{ml}$ \\
\hline Lactate dehidrogenase & 204 IU/1 & Adenosine deaminase & $7.9 \mathrm{IU} / \mathrm{I}$ \\
\hline Total cholester ol & $66 \mathrm{mg} / \mathrm{dl}$ & Hyaluronic acid & $8700 \mathrm{ng} / \mathrm{ml}$ \\
\hline Triglycerides & $8 \mathrm{mg} / \mathrm{dl}$ & Total cell count & $1924 / 3$ \\
\hline Na & $145 \mathrm{mM}$ & Band & $0.0 \%$ \\
\hline $\mathbf{K}$ & $4.4 \mathrm{mM}$ & Seg & $1.0 \%$ \\
\hline & & Lymph & $98.0 \%$ \\
\hline $\mathrm{Cl}$ & $113 \mathrm{mM}$ & Mono & $0.0 \%$ \\
\hline Amylase & $25 \mathrm{IU} / \mathbf{1}$ & Eosino & $0.0 \%$ \\
\hline \multirow[t]{2}{*}{ Glucose } & $142 \mathrm{mg} / \mathrm{dl}$ & Baso & $0.0 \%$ \\
\hline & & Macro & $1.0 \%$ \\
\hline
\end{tabular}

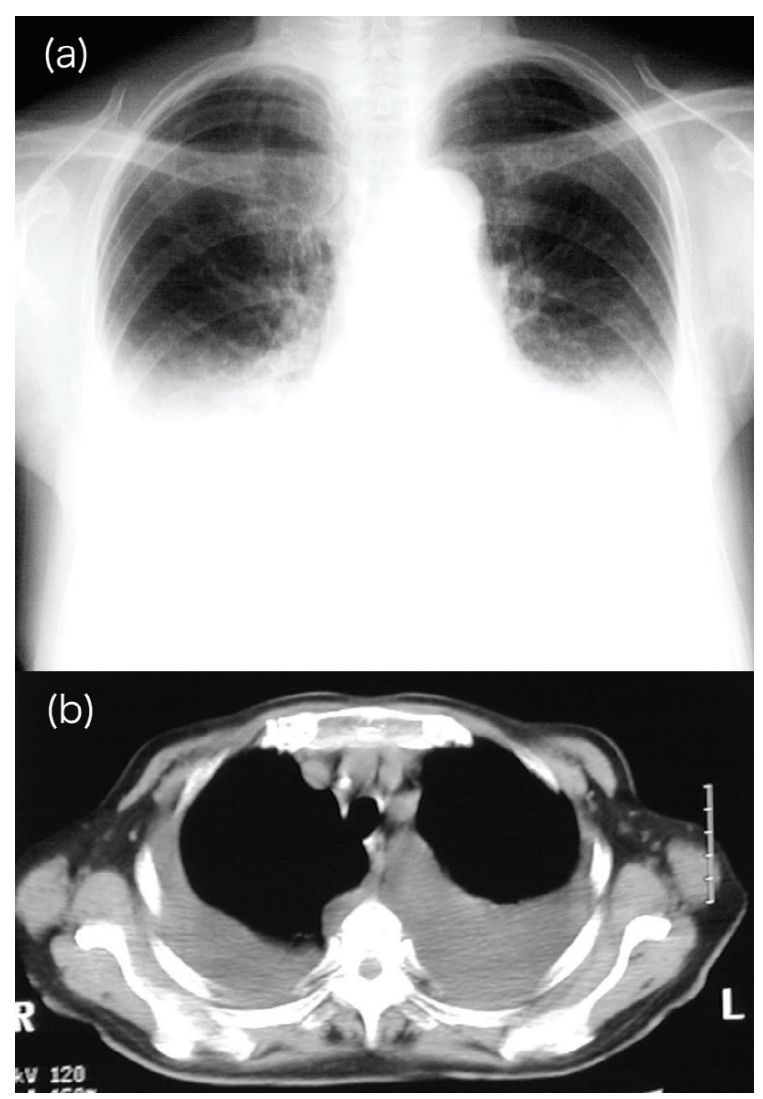

Figure 2. (a) A chest X-ray taken on admission shows blunting of bilateral costophrenic angles and meniscus signs. (b) Chest CT scan showing bilateral pleural fluid accumulation. No obvious inflammatory changes, tumors, or mediastinal lymph swelling was found.

Discussion

Idiopathic yellow nail syndrome, first described in 1964 (1), is characterized by the presence of yellow nails, lymphedema, and pulmonary disease, such as pleural effusion. It has been reported that congenital malformations and a secondary dysfunction of lymphatic vessels may be responsible for the syndrome, but the exact mechanism is still not known (2).

The pleural effusions associated with this disorder are often intractable; water deprivation or dietary restriction and the administration of diuretic drugs are not effective. In addition, since pleural fluid is rich in many proteins (3), frequent pleural fluid aspiration or drainage may cause hypoproteinemia or circulatory failure. Enlarging pleural effusions can be treated with pleurodesis (4), a pleuroperitoneal shunt (construction of a shunt from the pleural cavity to the abdominal cavity) (5), a pleurovenous shunt (construction of a shunt from the pleural cavity to a vein) (6), and oral octreotide (7); however, an effective therapy has not been established. Previously, pleurodesis using drugs like tetracycline, bleomycin, and cyclophosphamide has been tried for the treatment of yellow nail syndrome, but the treatment failed in 2 of 7 cases (4). Pleurodesis has also been reported to exacerbate lymphedema (8).

In the present patient, OK-432 was used for pleurodesis. OK-432 is a hemolytic streptococcal preparation that has been treated with penicillin. It is used in pleurodesis for carcinomatous pleurisy, and good treatment outcomes have been reported (9). It has been reported to be as efficacious as cisplatin with lower toxicity (10); it has also been re- 
ported to have better efficacy than mitomycin C (11). OK432 was chosen due to its low toxicity, since the patient required ventilator support. Pleurodesis with OK-432 has prevented accumulation of pleural fluid for a relatively long time. During the patient's clinical course, no exacerbation of lymphedema was observed. Pleural effusion associated with yellow nail syndrome is considered to be difficult to treat, but, given our results, pleurodesis with OK-432 could be used to treat the disease in the future.

\section{References}

1. Samman PD, White WF. The 'Yellow nail' syndrome. Br J Dermatol 76: 153-157, 1964.

2. Bull RH, Fenton DA, Mortimer PS. Lymphatic function in the yellow nail syndrome. Br J Dermatol 134: 307-312, 1996.

3. D’Alessandro A, Muzi G, Monaco A, Filiberto A, Barboni A, Abbritti G. Yellow nail syndrome: does protein leakage play a role? Eur Respir J 17: 149-152, 2001.

4. Jiva TM, Poe RH, Kallay MC. Pleural effusion in yellow nail syndrome: chemical pleurodesis and its outcome. Respiration 61: 300-302, 1994.

5. Brofman JD, Hall JB, Scott W, Little AG. Yellow nails, lymphedema and pleural effusion. Treatment of chronic pleural effusion with pleuroperitoneal shunting. Chest 97: 743-745, 1990.

6. Tanaka E, Matsumoto K, Shindo T, Taguchi Y. Implantation of a pleurovenous shunt for massive chylothorax in a patient with yellow nail syndrome. Thorax 60: 254-255, 2005.

7. Makrilakis K, Pavlatos S, Giannikopoulos G, Toubanakis C, Katsilambros N. Successful octreotide treatment of chylous pleural ef- fusion and lymphedema in the yellow nail syndrome. Ann Intern Med 141: 246-247, 2004.

8. Kawano T, Matsuse H, Shigematsu K, Miyazaki M, Taguchi T, Kohno S. Chemical pleurodesis could exacerbate lymphedema of yellow nail syndrome. Acta Medica Nagasakiensia 48: 71-72, 2003.

9. Kasahara K, Shibata K, Shintani H, et al. Randomized phase II trial of OK-432 in patients with malignant pleural effusion due to non-small cell lung cancer. Anticancer Res 26: 1495-1499, 2006.

10. Shimizu T, Takahashi N, Terakado M, et al. Comparison of intrapleural OK-432 and cisplatin for malignant pleural effusion in lung cancer patients. Jpn J Cancer Chemother 32: 1139-1143, 2005.

11. Luh KT, Yang PC, Kuo SH, Chang DB, Yu CJ, Lee LN. Comparison of OK-432 and mitomycin C pleurodesis for malignant pleural effusion caused by lung cancer. A randomized trial. Cancer 69: 674-679, 1992.

(C) 2007 The Japanese Society of Internal Medicine http://www.naika.or.jp/imindex.html 